\title{
Surface-Anchored Metal-Organic Frameworks as Versatile Resists for Gas-Assisted E-Beam Lithography: Fabrication of Sub-10 Nanometer Structures
}

\author{
Martin Drost ${ }^{\S}$ Fan Tu, ${ }^{\S}$ Luisa Berger, ${ }^{\S, \perp}$ Christian Preischl, ${ }^{\S}$ Wencai Zhou, ${ }^{\dagger}$ Hartmut Gliemann, ${ }^{\dagger}$ \\ Christof Wöll, ${ }^{\dagger}$ and Hubertus Marbach ${ }^{*}, \S$ \\ ${ }^{\S}$ Physikalische Chemie II, FAU Erlangen Nürnberg, Egerlandstrasse 3, 91058 Erlangen, Germany \\ ${ }^{\dagger}$ Institut für Funktionelle Grenzflächen, Karlsruher Institut für Technologie (KIT), Hermann von Helmholtz Platz 1, 76344 \\ Eggenstein Leopoldshafen, Germany
}

\begin{abstract}
We demonstrate that surface anchored metal-organic frameworks (SURMOFs) are extraordinary well suited as resists for high resolution focused electron beam induced processing (FEBIP) techniques. The combination of such powerful lithographic protocols with the huge versatility of MOF materials are investigated in respect to their potential in nanostructures fabrication. The applied FEBIP methods rely on the local decomposition of $\mathrm{Fe}(\mathrm{CO})_{5}$ and $\mathrm{Co}(\mathrm{CO})_{3} \mathrm{NO}$ as precursors, either by the direct impact of the focused electron beam (electron beam induced deposition, EBID) or through the interaction of the precursor molecules with preirradiated/activated SURMOF areas (electron beam induced surface activation, EBISA). We demonstrate the huge potential of the approach for two different types of MOFs (HKUST 1 and Zn DPDCPP). Our "surface science" approach to FEBIP, yields well defined deposits with each investigated precursor/SURMOF combination. Local Auger electron spectroscopy reveals clean iron deposits from $\mathrm{Fe}(\mathrm{CO})_{5}$; deposits from $\mathrm{Co}(\mathrm{CO})_{3} \mathrm{NO}$ contain cobalt, nitrogen, and oxygen. EBISA experiments were successful with $\mathrm{Fe}(\mathrm{CO})_{5}$. Remarkably EBISA with $\mathrm{Co}(\mathrm{CO})_{3} \mathrm{NO}$ does not

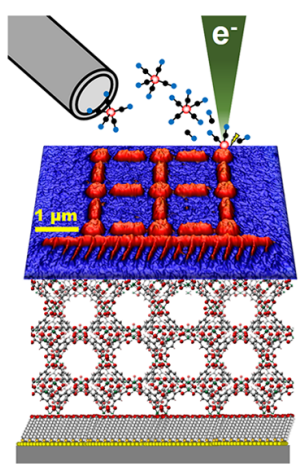
result in deposit formation on both resists, making the process chemically selective. Most importantly we demonstrate the fabrication of "nested L" test structures with $\mathrm{Fe}(\mathrm{CO})_{5}$ on HKUST 1 with extremely narrow line widths of partially less than $8 \mathrm{~nm}$, due to reduced electron proximity effects within the MOF based resists. Considering that the actual diameter of the electron beam was larger than $6 \mathrm{~nm}$, we see a huge potential for significant reduction of the structure sizes. In addition, the role and high potential of loading and transport of the precursor molecules within the porous SURMOF materials is discussed.
\end{abstract}

KEYWORDS: focused electron beam induced processing, surface anchored metal-organic frameworks, nanolithography, electron beam induced deposition, electron beam induced surface activation

T he controlled fabrication of arbitrarily shaped structures on the single digit nanoscale remains a major challenge. Focused electron beam induced processing (FEBIP) subsumes several powerful methods to fabricate such nanostructures on surfaces by manipulating matter with the focused electron beam of an electron microscope. ${ }^{1-6}$ The most prominent and "straightforward" FEBIP technique is electron beam induced deposition (EBID), where the electron beam locally dissociates precursor molecules, usually metal-organic compounds, which adsorb on a surface, leaving a deposit behind at the point of impact. ${ }^{1,46}$ The main advantage of EBID lithography is its flexibility, in terms of (i) the ability to directly deposit nanostructures with arbitrary shape and size, for example, for prototype fabrication, ${ }^{7,8}$ and (ii) the large amount of potential precursors and thus materials that can be deposited. ${ }^{4}$ Controlling the elemental composition of the deposits, however, is a major challenge in the field. ${ }^{5}$ Typically, nonmetallic precursor fragments resulting from the electron induced dissociation, as well as residual gas fragments are incorporated into the metal deposit, significantly altering its targeted properties such as high conductivity. To overcome this, an increasing amount of different methods to purify the deposits, either during or after deposition, have recently been demonstrated. ${ }^{5,9-14}$ 


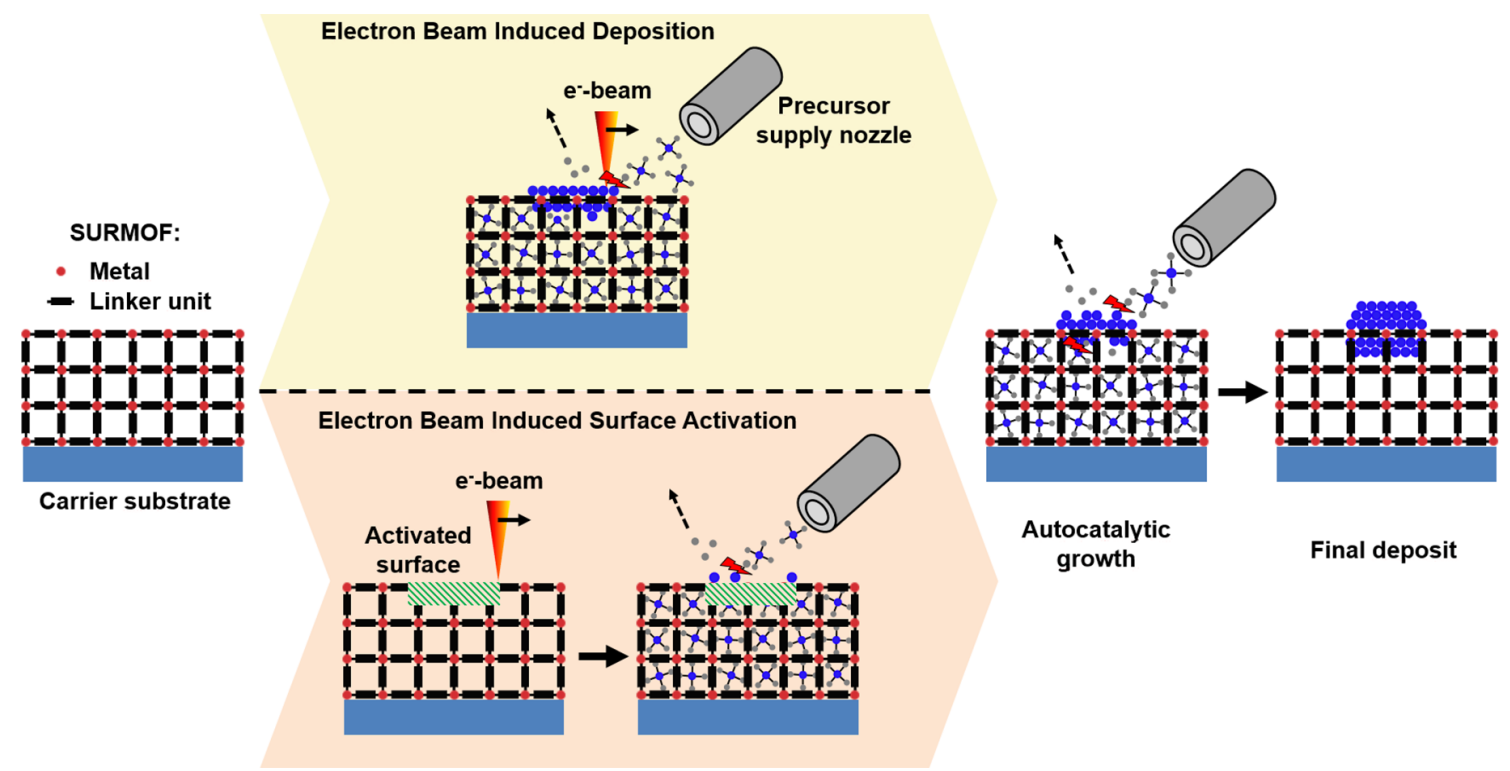

Figure 1. Schematics of the EBID and EBISA experiments conducted on SURMOFs presented in this work. In EBID (above the dashed line), the electron beam of the scanning electron microscope irradiates the SURMOF in the presence of a precursor gas, leaving behind a deposit. In EBISA (below the dashed line), the SURMOF is irradiated in the absence of a precursor, leading to a chemically modified, activated surface. Subsequently a dosed precursor can dissociate at activated sites, also leaving behind a deposit or a seed layer, respectively. In an autocatalytic growth process, the initial deposits fabricated by either method grow in size as long as the precursor is supplied.

Another important aspect in FEBIP are proximity effects: due to scattering of the primary electrons in the substrate or in already deposited material, forward scattered, back scattered, and secondary electrons cross the substrate-vacuum interface at areas away from the impact point of the primary beam, also leading to precursor dissociation and thus effective broadening of the deposit. ${ }^{15,16}$ These proximity effects depend on various parameters and increase for example, as easily comprehensible, generally with the applied electron dose. 4,6,15,16 Typical dimensions of EBID structures are in the range of $\sim 20 \mathrm{~nm}$ to several micrometers. ${ }^{17,18}$ With additional effort, it is possible to write sub $10 \mathrm{~nm}$ EBID structures, for example by using extremely narrow electron beams, ${ }^{17-20}$ ultrathin samples ${ }^{19}$ (reduction of electron interaction volume), SEM synchroniza tion with power line (see also discussion in context with Figure 5 below $)^{20}$ and post treatments such as gas assisted electron beam induced etching. ${ }^{17}$ Details on these results will be discussed in the context of our results below.

Recently an additional tool was introduced to the FEBIP family with the so called electron beam induced surface activation (EBISA). ${ }^{21,22}$ In EBISA, a suitable surface, for example, silicon oxide, ${ }^{23,24}$ rutile $\mathrm{TiO}_{2}(110),{ }^{25}$ or an organic layer, $^{26,27}$ is irradiated and, as a consequence, chemically modified without precursor dosage. In a second "development" step, the precursor is dosed and dissociates at the preirradiated, activated sites, yielding the formation of a localized deposit. In this regard, the EBISA technique is more closely related to classical photolithography since it consists of two consecutive steps: (1) exposure (electron irradiation compares to photon exposure) and (2) development process (precursor dosage via gas phase compares to the wet chemical development process in photolithography). As there is no electron irradiation necessary for precursor dissociation, the formation of massive deposits in EBISA relies on catalytic effects, that is, autocatalytic growth (AG) of the seed layer during additional precursor dosage. In this context, the EBISA process itself only comprises the catalytic fabrication of the seed layer; that is, without subsequent AG the deposit would be restricted to an extremely thin structure. Until now, EBISA has been shown to work with the precursors $\mathrm{Fe}(\mathrm{CO})_{5}$ and $\mathrm{Co}(\mathrm{CO})_{3} \mathrm{NO}$ in $\mathrm{UHV}^{22,25-28}$ and $\mathrm{Co}_{2}(\mathrm{CO})_{8}$ in $\mathrm{HV}^{24}$ In the case of $\mathrm{Fe}(\mathrm{CO})_{5}$, the autocatalysis, which can also occur on deposits fabricated with EBID, reliably leads to the formation of nearly pure, crystalline iron deposits. $^{21-23}$

In this work, we expand the field of FEBIP to a unexplored class of resists, namely surface anchored metal-organic frame works (SURMOFs). ${ }^{29,30}$ Metal-organic frameworks $(\mathrm{MOF} s)^{31,32}$ are crystalline coordination polymers consisting of metal or metal oxo ions connected by organic linkers and are typically fabricated by solvothermal synthesis. These framework materials are obtained in the form of powders, are highly porous and are therefore used, for example, for gas storage, purification, separation, as well as for catalysis. ${ }^{33-36}$ The outstanding flexibility in terms of the functionality of the porous material is due to the ability to precisely tune the properties of MOFs, such as the pore shape and the pore size as well as the chemical pore properties (reactivity, polarity) by varying the building blocks. This fact creates an application potential for optical and electronic applications, as well as for the fabrication of sensors. ${ }^{37}$ In 2009, Shekhah et al. described a procedure to mount MOFs on a gold substrate chemically functionalized with a self assembled monolayer (SAM). ${ }^{38}$ By subsequent and repeated dipping this substrate in separate solutions containing the metal ions and organic ligands, SURMOFs can be grown by liquid epitaxy in a controlled layer by layer (lbl) fashion. This method gives even more control over the composition of the framework, in terms not only of the thickness of the SURMOF layer-which depends on the number of deposition cycles-but also of the vertical sequence of different SURMOFs as the solutions used for the SURMOF growth can contain different building blocks resulting in so called heteroepitaxial SURMOFs. ${ }^{39}$ The latter 


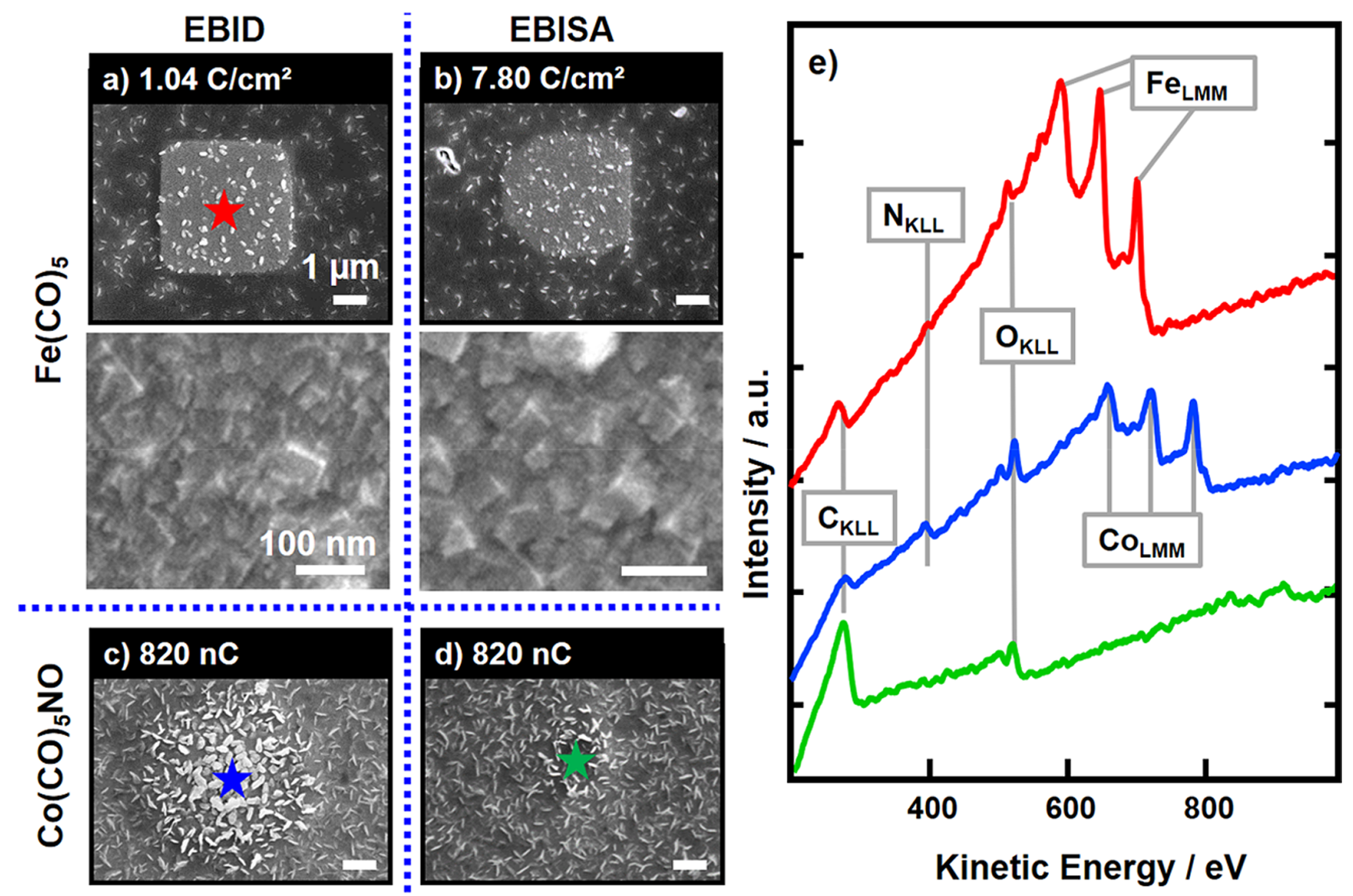

Figure 2. Results of FEBIP experiments followed by autocatalytic growth on the SURMOF zinc 5,15 diphenyl 10,20 di(4 carboxyphenyl) porphyrin (Zn DPDCPP). (a) SEM image of a $4 \times 4 \mu \mathrm{m}^{2}$ deposit fabricated by EBID with $\mathrm{Fe}(\mathrm{CO})_{5} ; t_{\mathrm{AG}}=245$ min and below a zoom in of the upper right corner of the deposit; (b) $4 \times 4 \mu \mathrm{m}^{2}$ deposit fabricated by EBISA with $\mathrm{Fe}(\mathrm{CO})_{5}$ and below a zoom in of the upper right corner of the deposit; (c) point deposit fabricated by EBID with $\mathrm{Co}(\mathrm{CO})_{3} \mathrm{NO} ; t_{\mathrm{AG}}=241 \mathrm{~min}$; (d) point deposit fabricated by EBISA with $\mathrm{Co}(\mathrm{CO})_{3} \mathrm{NO}$; (e) local AE spectra recorded at the positions indicated with respectively colored stars. The scale bars in panels a-d represent 1 $\mu \mathrm{m}$ and correspondingly $100 \mathrm{~nm}$ in the zoom ins as indicated.

aspect is opposed to the conventional solvothermal synthesis of MOFs, in which the solutions containing the building blocks are mixed at elevated temperatures.

From the FEBIP perspective, their specific properties make SURMOFs highly attractive substrates for this high resolution lithographic technique. An important motivation to use SURMOFs in FEBIP is their anticipated potential to reduce electron proximity effects, one of the main problems limiting resolution in e beam lithography. ${ }^{4,6,15,16}$ First, the lower density of SURMOFs, compared to that of bulk materials commonly used in FEBIP, is expected to reduce electron backscattering and thus strongly reduce proximity effects. Second, the organic ligands in the MOF are anticipated to quench low energy secondary electrons generated during the impact of the high energy primary electrons. This effect can be simply understood by considering the inherent reduced electron transport in organic materials compared to the usually conducting bulk substrates. ${ }^{26}$ These secondary electrons have a high cross section for precursor dissociation, leading to a decrease in resolution since they are emitted in all directions. ${ }^{20}$ Such quenching has been reported before for other organic molecules, such as porphyrins. ${ }^{26,27}$

Another appealing aspect of SURMOFs is their high porosity, which can be modified by the use of linkers with different sizes. We anticipate that the porosities of the two used types of SURMOFs is sufficient to enable the precursor molecules $\mathrm{Fe}(\mathrm{CO})_{5}$ and $\mathrm{Co}(\mathrm{CO})_{3} \mathrm{NO}$ to diffuse into the MOF materials. ${ }^{40,41}$ This property is expected to lead to additional precursor transport channels, that is, precursor transport through the SURMOF bulk in addition to the classical transport channels via the gas phase and surface diffusion. The corresponding precursor transport might severely affect the FEBIP process, as on standard bulk substrates deposition in EBID is often transport limited. This property of the SURMOFs consequently enables to load and deposit precursor materials inside the SURMOF as sketched in Figure 1. By varying the electron beam energy and therefore changing the electron interaction volume, one might even be able to control the depth of the deposit, potentially enabling controlled deposition in three dimensions. In addition, the $\mathrm{lbl}$ method allows realization of heteromultilayers, ${ }^{39}$ which might expand FEBIP to selective precursor loading and deposition of material in dedicated layers.

Figure 1 depicts a schematic outline of the explorative experiments presented in this work. EBID and EBISA experiments with the precursors $\mathrm{Fe}(\mathrm{CO})_{5}$ and $\mathrm{Co}(\mathrm{CO})_{3} \mathrm{NO}$, typically followed by autocatalytic growth, have been conducted on two different SURMOFs: Copper benzene 1,3,5 tricarbox ylate (HKUST 1) and zinc 5,15 diphenyl 10,20 di(4 


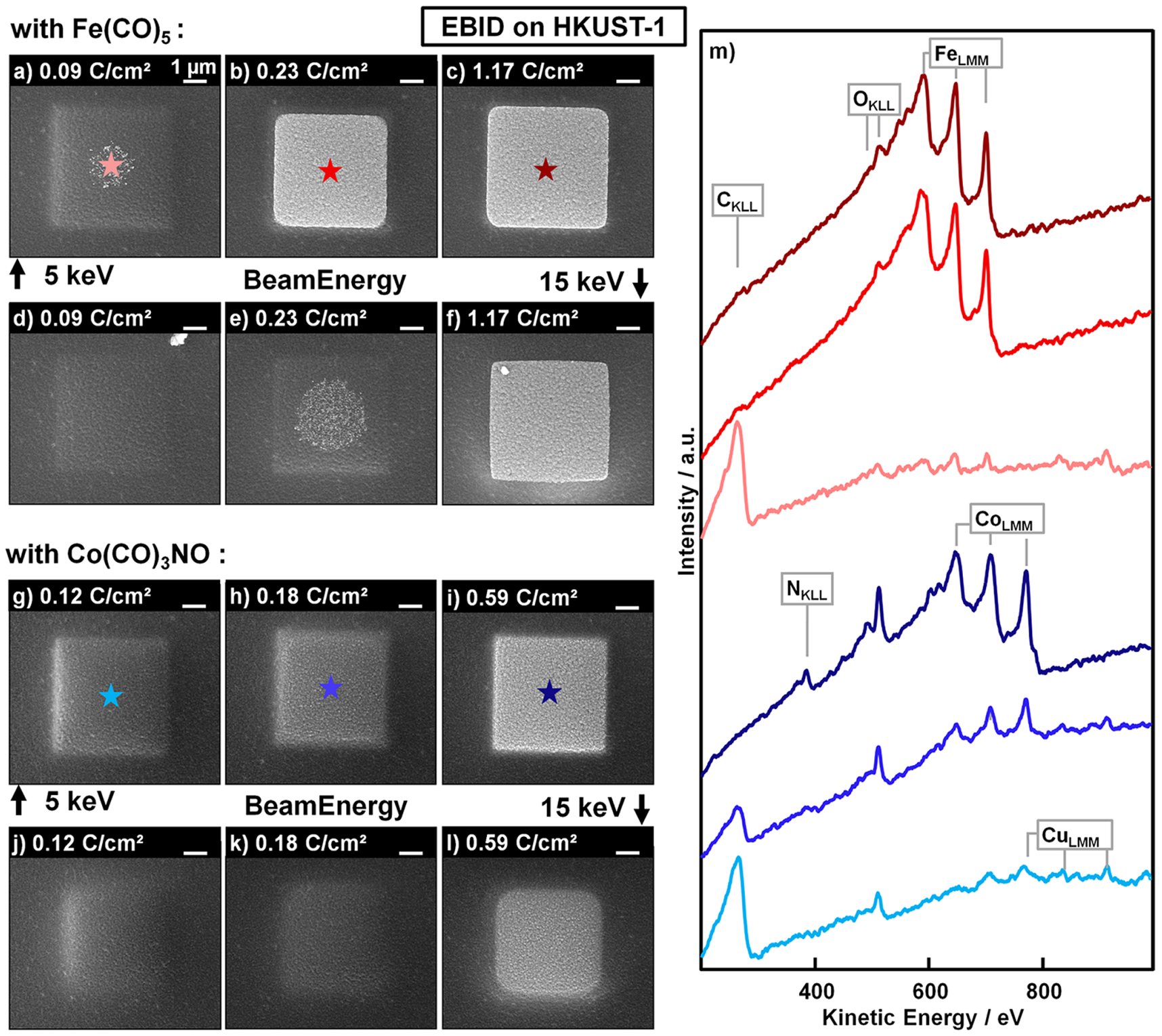

Figure 3. EBID on HKUST 1. All deposits are written with the indicated beam energy and $I_{\text {Beam }}=400 \mathrm{pA}$. (a-f) SE micrographs of $4 \times 4 \mu \mathrm{m}^{2}$ deposits fabricated from $\mathrm{Fe}(\mathrm{CO})_{5}$ with the indicated electron doses and autocatalytic growth times $t_{\mathrm{AG}}$ of (a) $257 \mathrm{~min},(\mathrm{~b}) 247 \mathrm{~min},(\mathrm{c}) 238$ min, (d) $217 \mathrm{~min},(\mathrm{e}) 202 \mathrm{~min}$, (f) $191 \mathrm{~min}$. (g-l) $4 \times 4 \mu \mathrm{m}^{2}$ deposits fabricated from $\mathrm{Co}(\mathrm{CO})_{3} \mathrm{NO}$ with the indicated electron doses and autocatalytic growth times $t_{A G}$ of (g) 258 min, (h) $252 \mathrm{~min},(i) 241 \mathrm{~min},(j) 212 \mathrm{~min},(\mathrm{k}) 207 \mathrm{~min},(\mathrm{l}) 198 \mathrm{~min}$. (m) Local Auger Electron spectra recorded at the sites indicated with stars of the same color.

Supporting Information for schemes of the two SURMOFs). While HKUST 1 is a rather commonly used type of SURMOF, Zn DPDCPP was chosen as it is chemically similar to $2 H$ tetraphenylporphyrin (2HTPP), which, in the form of multilayers on different substrates, has been demonstrated to be a suitable substrate for EBID and EBISA. ${ }^{26,27}$ With this in mind, we also seek to evaluate potential similarities and differences in the FEBIP process between Zn DPDCPP and 2HTPP. The experiments in the work at hand were conducted in a specific "surface science" approach to FEBIP, that is, working in an ultrahigh vacuum instrumental setup under well defined conditions. This approach proved particularly success ful in the fabrication of clean metallic deposits and seems to be a prerequisite for conducting EBISA. In all FEBIP experiments the precursor dosage was conducted such that the background pressure was set to $3.0 \times 10^{-7} \mathrm{mbar}$, corresponding to a local pressure at the surface of $\sim 9 \times 10^{-6} \mathrm{mbar}$ (see Experimental Section). The autocatalytic growth time for all EBISA structures was $270 \mathrm{~min}$, and is given in the respective figure captions for EBID structures. In this context, it should be pointed out that we mostly rely on AG for the formation of the deposit and the EBID process is mainly used to fabricate a seed layer in contrast to conventional EBID.

Overall, the goal of the present study is to explore the combination of the top down FEBIP approach with SURMOFs fabricated by bottom up techniques. With this approach, we aim toward the fabrication of complex functional nanostruc tures.

\section{RESULTS AND DISCUSSION}

EBID and EBISA on Zn-DPDCPP. First, the results of EBID and EBISA experiments and subsequent AG with both 
precursors on a Zn DPDCPP SURMOF will be discussed. This substrate was the first choice, since it contains free base porphyrins which were found to be susceptible to EBISA prepared as multilayers on different bulk substrates, like $\mathrm{Ag}(111), \mathrm{Si}(111)$, and $\mathrm{TiO}_{2}(110) .^{26,27}$ Therefore, one might anticipate that also the Zn DPDCPP SURMOF bears a corresponding activation mechanism, thus acting as a electron sensitive resist in EBISA. Figure 2a depicts a SEM micrograph of a $4 \times 4 \mu \mathrm{m}^{2}$ square deposit fabricated from $\mathrm{Fe}(\mathrm{CO})_{5}$ by EBID and autocatalytic growth, the corresponding local Auger electron spectrum (AES) is plotted in red in Figure 2e.

Inspection of Figure 2 reveals that deposition is mainly confined to the irradiated area, and the autocatalytic growth process results in the formation of pure, crystalline iron, as evidenced by the typical "cubical" appearance ${ }^{22,23}$ in the corresponding blow ups in Figure $2 \mathrm{a}, \mathrm{b}$ as well as by the red spectrum in Figure 2e. The observed carbon signal of the latter might either originate from the SURMOF below, or from the peculiar elongated protrusions which are noticeable as a characteristic feature on the whole substrate. Figure $2 c$ depicts an SEM image of an EBID point deposit, that is, an area where the beam dwelled stationary at one position during deposition until a total electron dose of $820 \mathrm{nC}$ was accumulated. It was fabricated from the $\mathrm{Co}(\mathrm{CO})_{3} \mathrm{NO}$ precursor and autocatalytic growth was employed. Local AES (Figure 2e, blue spectrum) shows that the deposit consists of cobalt, oxygen, nitrogen, and a small amount of carbon. As expected, the deposit is roughly of circular shape with a radius that vastly extends that of the electron beam due to electron proximity effects. ${ }^{15,16}$ In addition, the material is deposited rather inhomogeneously due to the rough surface.

These experiments prove that the porphyrin based $\mathrm{Zn}$ DPDCPP SURMOF is suitable as a resist for EBID, even though the rough surface is a drawback regarding the fabrication of spatially well defined structures.

Further experiments were then conducted to evaluate whether such substrates are also suited for EBISA. Figure $2 b$ depicts an SEM micrograph of an EBISA deposit fabricated from $\mathrm{Fe}(\mathrm{CO})_{5}$ with subsequent autocatalytic growth. Growth of crystalline iron on the square shaped preirradiated area is observed, albeit not fully with the expected square shape. We explain this deviaton of the actual shape from that of the irradiated area by the rather irregular topography of the porphyrin based SURMOF thin film. However, it can be concluded that EBISA works for $\mathrm{Fe}(\mathrm{CO})_{5}$ in conncection with the porphyrin based SURMOF substrates and consequently a corresponding activation mechanism must exist.

Interestingly, EBISA did not work for the precursor $\mathrm{Co}(\mathrm{CO})_{3} \mathrm{NO}$ on the same substrate. Figure $2 \mathrm{~d}$ depicts an SE micrograph of a surface site after a point irradiation with 820 $\mathrm{nC}$, and subsequent autocatalytic growth. A slight brightness difference of the irradiated spot is observed in SEM, and the corresponding local $\mathrm{AE}$ spectrum (Figure 2e, green spectrum) exhibits only signals from Zn DPDCPP. This demonstrates that no material was deposited, meaning that EBISA did not work for $\mathrm{Co}(\mathrm{CO})_{3} \mathrm{NO}$ but for $\mathrm{Fe}(\mathrm{CO})_{5}$ on $\mathrm{Zn} \mathrm{DPDCPP}$. This chemical selectivity is unexpected since EBISA worked for both precursors on thin 2HTPP layers on different substrates. ${ }^{26,27}$ Consequently, this means that the sensitivity of the two precursors in respect to the electron irradiated SURMOF sites is significantly different, even though the precursors are somewhat similar. Furthermore, these results indicate that the electron induced modifications of the porphyrin SURMOF are different from those of the porphyrin layers. ${ }^{27}$

Overall the FEBIP experiments on Zn DPDCPP revealed that EBID and EBISA are possible, and exhibited an unexpected, pronounced precursor selectivity in EBISA. A major drawback of the porphyrin based SURMOF was the rough surface topography, which is an obvious obstacle in particular to achieve small deposits. The roughness can be understood if one inspects the molecular arrangement within the $\mathrm{Zn} \mathrm{DPDCPP} \mathrm{SURMOF.} \mathrm{The} \mathrm{porphyrins} \mathrm{are} \mathrm{linked} \mathrm{via} \mathrm{Zn}$ to form $2 \mathrm{D}$ extended one molecular thick sheets, and these sheets are oriented perpendicular to the supporting substrate and are organized in a laminar fashion. Within this SURMOF structure no solid linking occurs between the sheets. It can be speculated that displacements between these $2 \mathrm{D}$ porphyrin sheets might yield the observed rough surface. In contrast the very well investigated HKUST 1 SURMOF exhibits 3D coordination of its molecular building blocks and exhibits a rather smooth surface as evidenced by SEM data. ${ }^{42}$ Therefore, we choose HKUST 1 to further explore FEBIP on SURMOFs in more detail and in particular to evaluate the minimal resolution of deposits without interfering surface roughness.

EBID on HKUST-1. Next, the results of dedicated EBID experiments and subsequent autocatalytic growth on HKUST 1 will be presented and discussed. Figure 3 panels a-f show a series of SEM micrographs of $4 \times 4 \mu \mathrm{m}^{2}$ deposits.

The series of square deposits were written with two different beam energies ( 5 and $15 \mathrm{keV}$ ), each with a variation in the primary electron area dose as indicated in Figure 3. For low doses (Figure $3 \mathrm{a}, \mathrm{Fe}(\mathrm{CO})_{5}, 5 \mathrm{keV}, 0.09 \mathrm{C} / \mathrm{cm}^{2}$ ) one observes only a minor brightness difference between irradiated and nonirradiated areas. In addition, scattered crystallites appear in the central part. At higher electron doses $\left(3 \mathrm{~b}, \mathrm{c} ; 0.23 \mathrm{C} / \mathrm{cm}^{2}\right.$ and $1.17 \mathrm{C} / \mathrm{cm}^{2}$, respectively), deposition is observed on the entire irradiated area, except at its periphery. Proximity effects explain the small amount of deposition observed on nonirradiated areas.

Further evidence is provided by the local Auger electron spectra (AES) depicted in Figure $3 \mathrm{~m}$, which were acquired on the corresponding deposits (positions indicated in the SE micrographs by the respectively colored stars). The two deposits fabricated with higher electron doses consist predominantly of iron and contain only minor amounts of oxygen.

The deposits fabricated with the lowest electron dose, on the other hand, exhibit only small amounts of iron, as expected from their appearance in SEM. For deposits made with low doses, substrate signals dominate the spectrum, that is, very little material was deposited. The series of deposits written with a $15 \mathrm{keV}$ beam shows the same trend, that is, more deposition of nearly pure, crystalline iron at higher primary electron doses. However, compared to deposits written with the same primary electron dose but lower beam energy of $5 \mathrm{keV}$ (compare for example, Figure 2 panels $\mathrm{b}$ and e) we observe significantly less deposited material at $15 \mathrm{keV}$. Interestingly, the deposition of the same amount of material is shifted to higher electron doses for the higher primary electron energy of $15 \mathrm{kV}$ compared to 5 $\mathrm{kV}$.

Figure 3 panels $\mathrm{g}-1$ depict the results of EBID experiments for the other precursor, $\mathrm{Co}(\mathrm{CO})_{3} \mathrm{NO}$. Again $4 \times 4 \mu \mathrm{m}^{2}$ squares were irradiated with varying electron dose and two different electron beam acceleration voltages of $5 \mathrm{kV}$ and $15 \mathrm{kV}$. At first glance the trends appears to be the same as in the 
corresponding series of iron deposits: increased material deposition at higher primary electron doses and lower beam energies (compare the peripheries of the deposits in Figure 3 panels $i$ and $l$ and the fainter appearance of the squares in both $j$ and $\mathrm{k}$ ), and spatial selectivity of deposition to irradiated areas. Local AES shows that during the autocatalytic growth process, aside from cobalt, a significant amount of oxygen as well as nitrogen is incorporated into the deposit. In contrast, the deposits contain no carbon, as evidenced by the spectrum of the deposit written with $0.59 \mathrm{C} / \mathrm{cm}^{2}$, while the deposits written with lower doses are not thick enough to completely attenuating the carbon signal from the HKUST 1 layer below. In addition, as already observed for the EBID experiments with the iron precursor, also for the Co containing precursor the process appears to be fully selective, that is, no Co was found outside the electron affected areas.

The following conclusions can be drawn from the observations reported above. Using the EBID protocol and subsequent autocatalytic growth with $\mathrm{Fe}(\mathrm{CO})_{5}$ and $\mathrm{Co}$ (CO) ${ }_{3} \mathrm{NO}$ on a HKUST 1 SURMOF, spatially and chemically well defined structures can be obtained. With the experimental parameters used, deposition takes place once a critical effective electron dose is exceeded, where effective electron dose means the total number of PEs, SEs, and BSEs crossing the substratevacuum interface. Generally, electrons with lower energy have a higher cross section toward the decomposition of precursor molecules. This consideration is the key to understand the more effective deposition in EBID at lower primary electron beam energies. ${ }^{6}$ Conventional wisdom holds that a primary beam with lower energy yields more BSEs and SEs with also lower energies close to the impact point of the beam than a corresponding higher energy beam. This hypothesis combined with the higher cross section for precursor dissociation conclusively explains the higher deposition rate. In this context the onset of deposition in the center of the squares as observed for EBID with $\mathrm{Fe}(\mathrm{CO})_{5}$ is due to the nonprimary electrons which exhibit a spatial distribution with radial symmetry around the impact point of the primary beam. Consequently, the effective electron dose is then highest in the center of the square structures due to the agglomerated contributions of BSEs and SEs from all "neighboring" points irradiated with the primary beam.

The experiments performed on the porphyrin based SURMOF Zn DPDCPP show very similar results regarding spatial selectivity and elemental composition of the deposits, suggesting that SURMOFs are in general suitable substrates for EBID. At the given autocatalytic growth times for the structures depicted in Figure 3, i.e., in all cases significantly longer than 3 $\mathrm{h}$, one can safely assume that the vast majority of the material is deposited by AG. Therefore, it is no surprise that the elemental compositions of the deposits from both precursors reproduce the findings with the same precursors, but on different substrates, quite well. ${ }^{23,25,26,28}$ Consequently, the chemical nature of the autocatalytically grown material is obviously independent of the underlying substrate, which demonstrates the high potential of autocatalysis in FEBIP regarding the reproducibility of the elemental composition of the deposits.

After the comparably large $4 \times 4 \mu \mathrm{m}^{2}$ squares allowed for chemical analysis via local AES, one certainly wants to evaluate if the fabrication of more complex structures is also feasible. To do so, the lithographic fabrication of the graphics depicted in Figure 4a was realized via EBID + AG with varying electron doses and AG times. A selection of three results is presented in
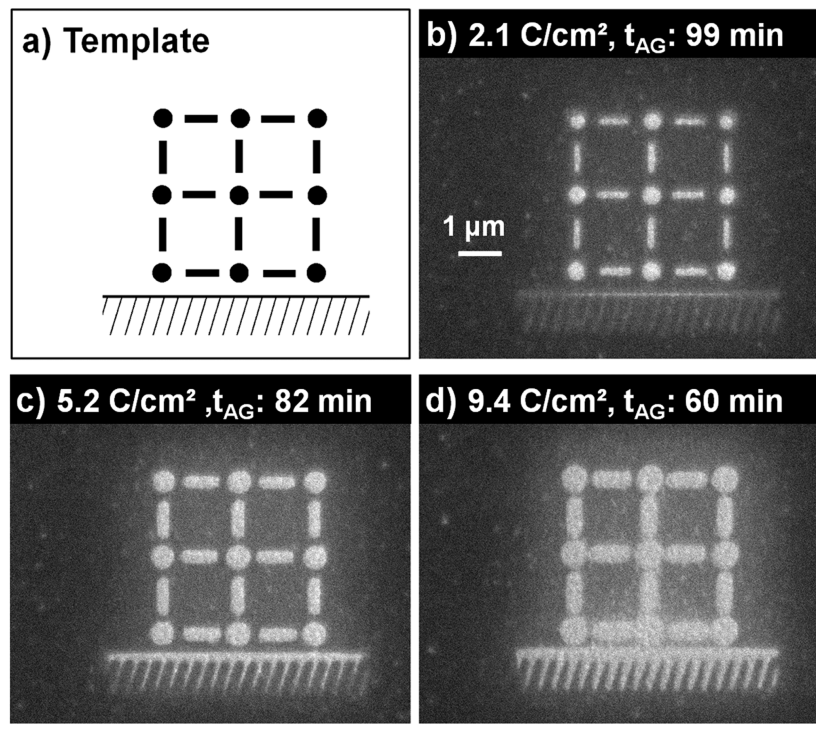

Figure 4. EBID with $\mathrm{Fe}(\mathrm{CO})_{5}$ on HKUST 1. All deposits written with $E_{\text {Beam }}=15 \mathrm{keV}$ and $I_{\text {Beam }}=400 \mathrm{pA}$. (a) Graphic of "SURMOF icon" as template for the deposits depicted in panels $b-d$. $(b-d)$ SE micrographs of corresponding deposits realized with the indicated electron doses and AG growth times.

Figure $4 \mathrm{~b}-\mathrm{d}$ as indicated with increasing electron doses but decreasing AG growth times. Overall, the deposits exhibit a pronounced contrast in SEM with sharp boundaries. However, electron proximity effects become evident for higher electron doses. Even though additional material deposition via AG is reduced due to shorter AG growth time, in Figure $4 \mathrm{~d}$ the deposit is clearly enlarged compared to the ones with lower electron dose but longer AG times depicted in Figure 4 panels $\mathrm{b}$ and $\mathrm{c}$. In particular, in the lower part of Figure $4 \mathrm{~d}$ the parts, which are separated in the template, start to merge. These observations can be safely assigned to electron proximity effects. However, in comparison with bulk surfaces previously investigated in our instrument, such as $\mathrm{Si}(111)^{27}$ and $\mathrm{TiO}_{2}(110),{ }^{25,27}$ the deposits on HKUST 1 are much more well defined, for example, sharper edges but in particular the lack of scattered deposits in close proximity to the point of impact of the primary beam is significant and certainly very advantageous for lithography. We interpret this as evidence that indeed the low density of the SURMOF material in combination with the proposed quenching of low energy secondary electrons is responsible for the latter observation.

High-Resolution Lithography. Encouraged by the results depicted in Figure 4 we investigated the resolution limit by illuminating even smaller structures on HKUST 1 with the precursor $\mathrm{Fe}(\mathrm{CO})_{5}$. To this end, a well established test structure to determine resolution in lithography, the so called nested L structure, was written. This structure consists of seven $\mathrm{L}$ shaped lines next to each other with minimal distance, with the central L slightly elongated. ${ }^{20}$ To optimize resolution, we had to optimize the EBID + AG process in an iterative process. First, the electron beam diameter had to be minimized. In this context we realized that best resolution of the SEM could be achieved with $6.3 \mathrm{~nm}$ at $E_{\text {Beam }}=20 \mathrm{keV}$ and $I_{\text {Beam }}=200 \mathrm{pA}$ according to the $20 / 80$ criterion (lateral distance in which the SEM intensity over the edge of a structure drops from $80 \%$ to $20 \%$, see Figure SI 4 in SI). Even though the estimated $6.3 \mathrm{~nm}$ is still small, the nominal best resolution of our instrument is $<3$ 
$\mathrm{nm}$ at $E_{\text {Beam }}=15 \mathrm{keV}$ and $I_{\text {Beam }}=400 \mathrm{pA}$, which indicates that the filament of the SEM was slightly degraded. The next step was to optimize the various lithographic parameters of the EBID process, for example, number of sweeps, waiting time between individual sweeps, variation of local and total primary electron dose by changing the step size and dwell times. Particular care was devoted to the consideration of proximity effects caused by the irradiation of neighboring lines. Therefore, the $\mathrm{L}$ shaped lines were irradiated with different electron doses, such that the outer lines were irradiated with higher and the inner lines with lower electron doses. Consequently, the electron doses given in the caption of Figure 5 cover the range of applied electron doses per nested L structure. In addition, it is also clear that the AG growth times must be reduced, since the AG also causes lateral widening of the deposits. The best result obtained after this process is depicted in Figure 5.

To quantify the obtained line width within the nested $L$ deposits, integrated gray value line profiles were measured. As an illustrative example, the profile extracted from the rectangle marked in green in Figure 5d is depicted in Figure 5e. An average full width at half maximum (fwhm) of $9.6 \mathrm{~nm}$ was measured for the structure shown. The corresponding analysis of the lines depicted in Figure 5a,c yielded average fwhm values of $11.7 \mathrm{~nm}$ for the vertical and $11.1 \mathrm{~nm}$ for the horizontal lines (c.f. Figure SI2 in the Supporting Information). The smaller line width estimated from Figure $5 \mathrm{~b} / \mathrm{d}$ compared to the ones in Figure $5 \mathrm{a} / \mathrm{c}$ are mainly due to $\sim 20 \%$ reduced AG times, while the corresponding electron doses are very similar. The smallest estimated line width with fwhm $7.5 \mathrm{~nm}$ demonstrates the potential of the method, since the diameter of the beam (6.3 nm, c.f. Supporting Information Figure SI4) is only slightly smaller. In other words, the smallest achievable structures are only $\sim 120 \%$ of the size of the spot diameter of the focused electron beam and in this regard establish a record value.

For comparison, one might consider the current world record fwhm values for individual dots of $0.7 \mathrm{~nm}$ and for lines of $1.9 \mathrm{~nm}$ which were both realized with a nominal electron beam spot size of $0.3 \mathrm{~nm}$, that is, with a factor of $>6$ in the case of the lines. ${ }^{19}$ In addition the latter results were achieved with the precursor $\mathrm{W}(\mathrm{CO})_{6}$ on $30 \mathrm{~nm}$ thick $\mathrm{Si}_{3} \mathrm{~N}_{4}$ membrane and the imaging was done via annular dark field imaging, which exhibits a strong $\mathrm{Z}$ contrast, eventually underestimating deposits from lighter elements such as carbon. Also for other high resolution deposits via EBID the written structures are in the best cases three times larger than the diameter of the used electron beam. ${ }^{18,20}$ Furthermore, the chemical nature of the deposits reported in the literature is mostly unclear or consisted of major amounts of carbon. ${ }^{18-20}$ In this regard, the local $\mathrm{AE}$ spectra in Figure 5f clearly demonstrates that we deposited significant amounts of $\mathrm{Fe}$.

However, regarding the size of the deposits, it is clear that the AES signals acquired over the indicated areas also must have contributions from the SURMOF. Therefore, the origin of the oxygen peak remains partially unclear, since it cannot be unambiguously assigned to neither the deposit nor the HKUST 1 substrate. In this regard, a reliable quantitative statement about the elemental composition of the line structures is not possible at this stage, but a significant deposition of $\mathrm{Fe}$ can be stated. Overall, we regard the extremely small Fe containing structures written on the SURMOF as a major breakthrough in terms of resolution in combination with the chemical nature of deposited material (significant metal content). It should also be mentioned that we were never able
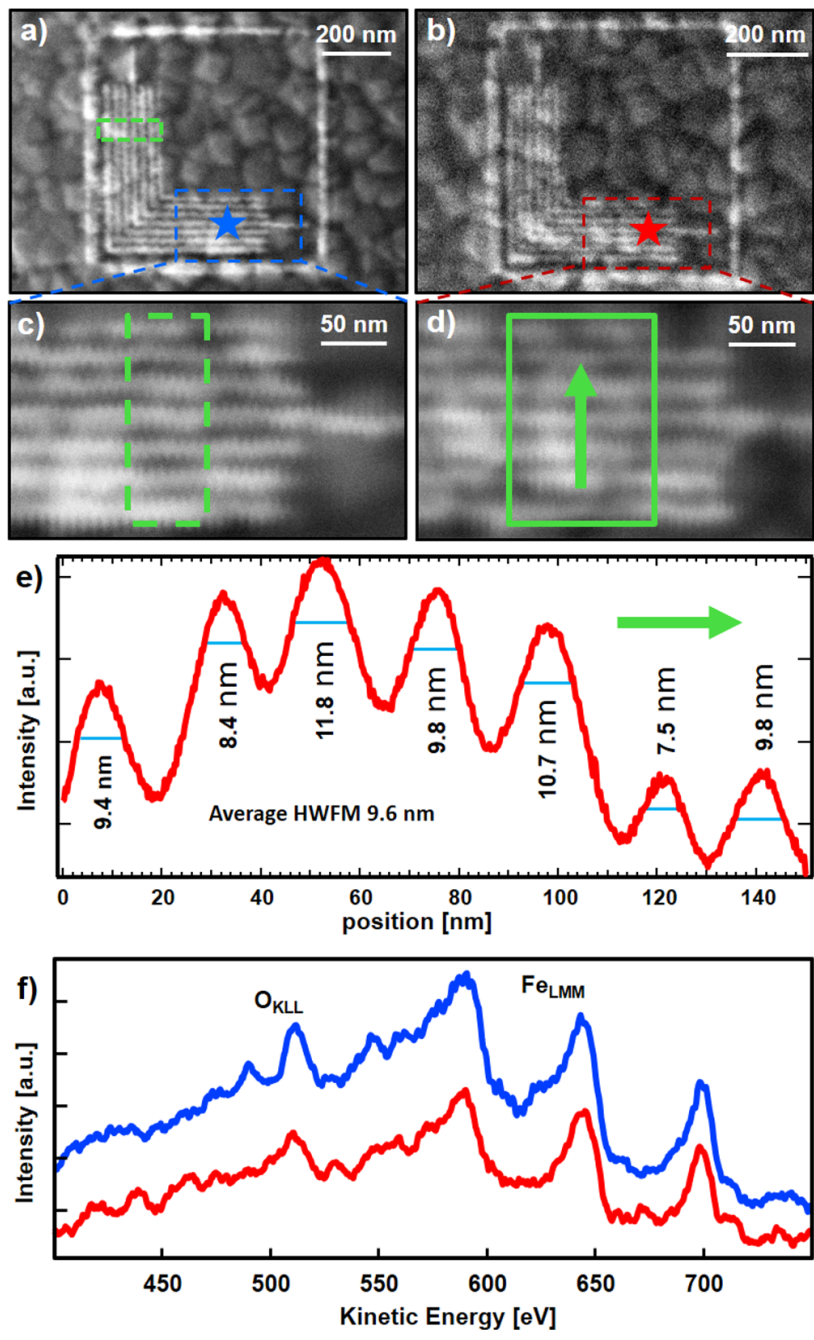

Figure 5. EBID with $\mathrm{Fe}(\mathrm{CO})_{5}$ on HKUST 1. All deposits written with $E_{\text {Beam }}=20 \mathrm{keV}$ and $I_{\text {Beam }}=200 \mathrm{pA}$. (a-d) Two selected "nested L" test structures and corresponding zoom ins obtained after tedious subsequent optimization procedures of the litho graphic process. (a,c) Fabricated with $2.4-36.5 \mu \mathrm{C} / \mathrm{cm}, 250$ sweeps, $t_{\mathrm{AG}}=21 \mathrm{~min} ;(\mathrm{b}, \mathrm{d})$ fabricated with $2.3-33.8 \mu \mathrm{C} / \mathrm{cm}, 250$ sweeps, $t_{\mathrm{AG}}=17 \mathrm{~min}$. (e) Integrated intensity line profile with correspondingly estimated fwhm values extracted from the high magnification SEM image depicted in panel d. A minimum fwhm line width of $7.5 \mathrm{~nm}$ is measured and the average value over all seven lines is $9.6 \mathrm{~nm}$ with a pitch of $23.6 \mathrm{~nm}$. The corresponding line width estimations for the regions indicated by the dashed green rectangles in in panels a and c can be found in the SI and yielded average $\mathrm{fwhm}$ values of $11.7 \mathrm{~nm}$ for the vertical and $11.1 \mathrm{~nm}$ for the horizontal lines with a pitch of $27.3 \mathrm{~nm}$. () Local AE spectra recorded at the positions indicated with the respectively colored rectangles in panels $a$ and $b$.

to produce lines smaller than $\sim 15 \mathrm{~nm}$ on conventional substrates in our instrument, even though the beam diameter was much smaller $(<3 \mathrm{~nm})$ in these experiments. This again evidence the superior FEBIP properties of the HKUST 1 in the present study. In addition, the blow ups in Figure $5 \mathrm{c}, \mathrm{d}$ document that at this point we reached the technical limit of the SEM instrument. The corresponding lines exhibit irregularities, which can be assigned to jitter of the electron beam, due to known in house mechanical vibrations of $\sim 49 \mathrm{~Hz}$. As demonstrated by van Oven et al., ${ }^{20}$ an effective counter 

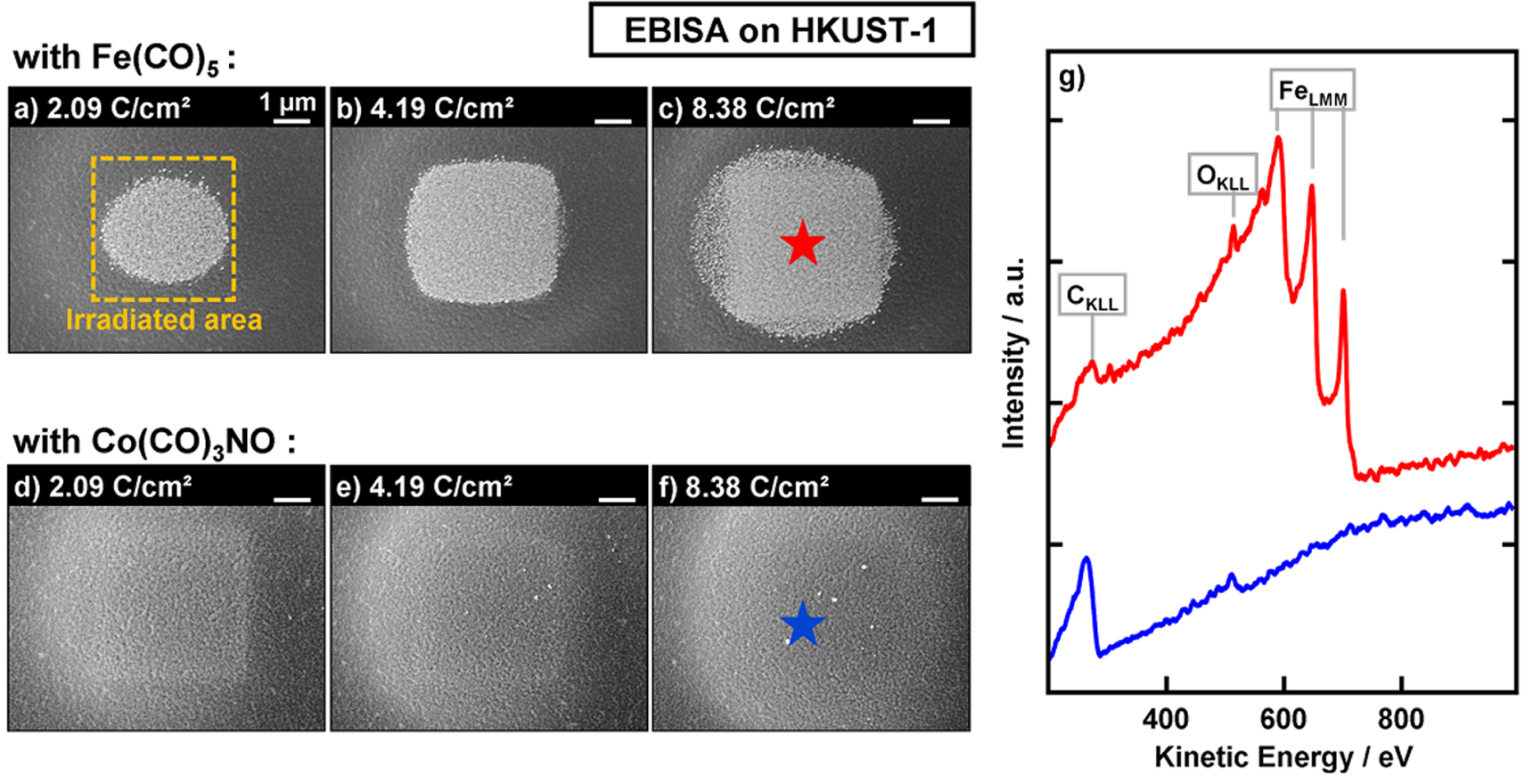

Figure 6. EBISA on HKUST 1. All structures written with $E_{\mathrm{Beam}}=20 \mathrm{keV}, I_{\mathrm{Beam}}=3 \mathrm{nA}, \mathrm{t}_{\mathrm{AG}}=270 \mathrm{~min}$. SE micrographs of $4 \times 4 \mu \mathrm{m}^{2}$ deposits fabricated from $(\mathrm{a}-\mathrm{c}) \mathrm{Fe}(\mathrm{CO})_{5}$ and $(\mathrm{d}-\mathrm{f}) \mathrm{Co}(\mathrm{CO})_{3} \mathrm{NO}$ with the indicated electron doses. $(\mathrm{g})$ Local Auger electron spectra recorded at the sites indicated with the respectively colored stars. They confirm that EBISA with $\mathrm{Fe}(\mathrm{CO})_{5}$ was successful, resulting in deposits consisting of clean iron, while no deposition of Co could be verified when using $\mathrm{Co}(\mathrm{CO})_{3} \mathrm{NO}$.

measure would be a phase synchronization of each sweep by introducing according waiting times between individual sweeps (SEM synchronization with power line). If these challenges can be overcome, we think that SURMOFs in general are suitable substrates to fabricate nanostructures by FEBIP, with the limiting factor for further downscaling being the beam spot size.

EBISA on HKUST-1. Finally, it should be evaluated if HKUST 1 is also a uitable resist for EBISA, that is, bears a corresponding activation mechanism to selectively decompose the precursor molecules. Figure 6 depicts SE micrographs of two series of $4 \times 4 \mu \mathrm{m}^{2}$ electron irradiated squares subsequently exposed to $\mathrm{Fe}(\mathrm{CO})_{5}$ (Figure $6 \mathrm{a}-\mathrm{c}$ and $\mathrm{Co}$ $(\mathrm{CO})_{3} \mathrm{NO}$ (Figure $6 \mathrm{~d}-\mathrm{f}$ ) on HKUST 1 .

In the case of $\mathrm{Fe}(\mathrm{CO})_{5}$, deposited material can be clearly distinguished in SEM, and the presence of $\mathrm{Fe}$ is confirmed with local AES (Figure 6g), proving that EBISA was successful. Similar to EBID, we observe deposition in the center of the irradiated area at relatively low primary electron doses $(2.09 \mathrm{C} /$ $\mathrm{cm}^{2}$, Figure $6 \mathrm{a}$ ), whereas at increasing doses, $\mathrm{Fe}$ is deposited on the complete irradiated area and eventually outside of it due to proximity effects. Again, autocatalytic growth leads to the formation of cubic Fe crystals, while only minor carbon and oxygen impurities are detected in local AES. On the contrary, irradiated areas that have been exposed to $\mathrm{Co}(\mathrm{CO})_{3} \mathrm{NO}$ do not exhibit a pronounced contrast in SEM, aside from what is to be identified with beam damage. Local AES performed in the area that has been irradiated with the highest electron dose $(8.38 \mathrm{C}$ / $\mathrm{cm}^{2}$ ) only shows signals from HKUST 1 , confirming that no deposition occurred. Overall HKUST 1 exhibits qualitatively the same behavior as observed to the Zn DPDCPP SURMOF.

To gain more insight into the activation mechanism that leads to the dissociation of $\mathrm{Fe}(\mathrm{CO})_{5}$, the influence of electron beam irradiation on HKUST 1 was studied. To do so, AE spectra were recorded while scanning the pristine surface with different agglomerated electron area doses, which allows following potential intensity changes of the substrate $\mathrm{AE}$ signals as a function of the electron area dose. No significant changes in the $\mathrm{C}_{\mathrm{KLL}}$ and $\mathrm{Cu}_{\mathrm{LMM}}$ signal intensities were observed, but for $\mathrm{O}_{\mathrm{KLL}}$, depicted in Figure SI3a (see Supporting Information). Here, a series of corresponding $\mathrm{AE}$ spectra recorded with different scan areas is depicted, corresponding to applied electron area doses ranging from $3.6 \times 10^{-3} \mathrm{C} / \mathrm{cm}^{2}$ to $1.3 \times 10^{6} \mathrm{C} / \mathrm{cm}^{2}$. One observes a significant decrease in the $\mathrm{O}_{\mathrm{KLL}}$ peak area toward higher electron doses, which is also apparent from Figure SI3 b), where the normalized peak areas are plotted against the applied electron area dose. Thus, the topmost layers of the HKUST 1 become depleted of oxygen, and increased signals of carbon and copper remain.

These findings show that HKUST 1 and also Zn DPDCPP are very suitable resists to fabricate clean iron nanostructures from $\mathrm{Fe}(\mathrm{CO})_{5}$ using EBISA and $\mathrm{AG}$, while there are no signs that $\mathrm{Co}(\mathrm{CO})_{3} \mathrm{NO}$ decomposes at preirradiated surface sites. This further expands the range of substrates suitable for EBISA to SURMOFs in general. The catalytic activity resulting from the electron beam irradiation is completely selective toward decomposition of only one of the investigated precursors, which is an interesting property, for example, when working with precursor mixtures, as it might allow for selective deposition of only one material. Our results also provide some insight into the effect of high energy electron irradiation on HKUST 1, but the exact chemical nature of the dissociation products remains speculative. One mechanism leading to oxygen removal might be an electron induced $\mathrm{C}-\mathrm{C}$ bond scission between aromatic and carboxylic carbon atoms, followed by release of $\mathrm{CO}_{2}$. Similar to what has been observed for electron irradiation of different organic compounds on surfaces, ${ }^{43-46}$ other reactions might involve $\mathrm{C}-\mathrm{C}$ and $\mathrm{C}-\mathrm{H}$ bond scissions, leading to for example, cross linking of aromatic 
fragments and formation of reactive radical and ionic species which then initiate precursor dissociation and nucleation. One might also speculate if exposed $\mathrm{Cu}$ atoms are the active sites for $\mathrm{Fe}(\mathrm{CO})_{5}$ decomposition. Furthermore, it should be noted that even though both investigated SURMOFs are obviously chemically altered by electron irradiation, we did not observe any indications in SEM for a significant decay of the SURMOF structures.

\section{SUMMARY}

In conclusion we demonstrate that SURMOFs are extremely promising substrates/resists for FEBIP lithography. EBID and EBISA experiments applied to these heteroresists with the precursors $\mathrm{Fe}(\mathrm{CO})_{5}$ and $\mathrm{Co}(\mathrm{CO})_{3} \mathrm{NO}$ were conducted on HKUST 1 and Zn DPDCPP SURMOFs. For all precursor/ substrate combinations the EBID experiments yielded well defined nanostructures, obtaining clean iron deposits with $\mathrm{Fe}(\mathrm{CO})_{5}$, and cobalt deposits with oxygen and nitrogen contributions from $\mathrm{Co}(\mathrm{CO})_{3} \mathrm{NO}$. In all cases, prolonged autocatalytic growth was used. One significant result is the fabrication of nested L structures with fwhm lines with $7.5 \mathrm{~nm}$, albeit using a focused electron beam with an estimated diameter of $6.3 \mathrm{~nm}$. This establishes, to the best of our knowledge, a record value concerning the relation of the written structure to the electron beam size $(\sim 120 \%)$. This finding demonstrates that electron proximity effects can be significantly suppressed using the highly porous SURMOFs as substrates, thus enabling the fabrication of extraordinary small structures. The reason for this favorable behavior is explained by the low density of the material and the effective quenching of low energy secondary and backscattered electrons released from the SURMOF/bulk substrate interface. From these results, it is clear, that working with a narrower focused electron beam has the potential to write even significant smaller structures. EBISA experiments on both SURMOFs as resists were successful with $\mathrm{Fe}(\mathrm{CO})_{5}$, yielding clean iron deposits after autocatalytic growth, but no deposition was observed when using EBISA with $\mathrm{Co}(\mathrm{CO})_{3} \mathrm{NO}$. This finding has an especially high application potential since it makes the process selective with respect to the chemistry of the two apparently similar precursors. Even though the activation mechanism remains speculative, we found that electron irradiation of HKUST 1 leads to a loss of oxygen, which might yield reactive, exposed $\mathrm{Cu}$ atoms, which might be effective for selective dissociation of the iron precursor. In addition, the generation of reactive carbon species was discussed as a possible source for the electron induced reactivity. Furthermore, it should be stated that the anticipated diffusion and loading of precursor materials is a particularly interesting aspect of SURMOFs, which might open up additional precursor transport channels and bears extremely high potential for further exploration, for example, to fabricate 3D nanodeposits within the SURMOF bulk.

Overall, the presented results are a very promising to further develop techniques for the fabrication of complex functional nanostructures, which might include but are not restricted to the writing of nanoscale metallic structures in SURMOFs for magnetic and electronic applications and FEBIP deposition of metallic templates for the localized growth of SURMOFs either on bulk or SURMOF substrates.

\section{EXPERIMENTAL SECTION}

All FEBIP experiments were performed in a commercial UHV system (Multiscanlab, Omicron Nanotechnology, Germany) with a base pressure of $p<2 \times 10^{-10} \mathrm{mbar}$. The main component of the analysis chamber is a UHV compatible electron column (Leo Gemini) for scanning electron microscopy (SEM) with an estimated resolution of $\sim 7 \mathrm{~nm}$ at $E_{\text {Beam }}=20 \mathrm{keV}$ and $I_{\text {Beam }}=200 \mathrm{pA}$, in combination with a hemispherical electron energy analyzer, also local $\mathrm{AE}$ spectroscopy (AES) and scanning Auger microscopy (SAM) can be conducted. Iron pentacarbonyl $\left(\mathrm{Fe}(\mathrm{CO})_{5}\right)$ was purchased from ACROS Organics, cobalt tricarbonyl nitrosyl $\left(\mathrm{Co}(\mathrm{CO})_{3} \mathrm{NO}\right)$ was obtained from abcr $\mathrm{GmbH} \& \mathrm{Co}$. KG. The quality of the precursor gas was analyzed with a quadrupole mass spectrometer in a dedicated gas analysis chamber (base pressure $<2 \times 10^{-9} \mathrm{mbar}$ ). The precursor gas was dosed through a nozzle with an inner diameter of $3 \mathrm{~mm}$, and a distance of approximately $12 \mathrm{~mm}$ to the sample surface. On the basis of the simulations with the software GIS Simulator (version 1.5$)^{47}$ we estimated the factor for local pressure increase on the sample surface to about 30. For a fixed background pressure of $3.0 \times 10^{-7} \mathrm{mbar}$ this corresponds to a local pressure at the surface of about $9 \times 10^{-6} \mathrm{mbar}$. The autocatalytic growth time, electron beam energy, and current during lithography is depicted in the figure caption of the respective SE micrograph. The lithographic processes were controlled via a home built lithography application based on LabView 8.6 (National Instruments) and a high speed DAC PCIe card (M2i.6021 exp, Spectrum GmbH, Germany). All given electron doses were corrected to account for probe current deviations which were measured using a faraday cup. SEM images were acquired with SmartSEM (Zeiss) and are shown with minor contrast and brightness adjustments only. For Auger electron spectroscopy the electron beam of the SEM was used as ionization source, with a beam energy of $15 \mathrm{keV}$ and a nominal probe current of $3 \mathrm{nA}$. Spectra were recorded with a hemispherical electron energy analyzer (EA125, Omicron Nanotechnology) and Matrix 3.1 (Omicron Nanotechnology). Data processing was performed with Igor Pro 6.22A (Wavemetrics). The integrated line profile was measured using ImageJ 1.44 p. Laser cut $\mathrm{Si}(100)$ wafers were purchased from the Institute of Electronic Materials Technology/ Warsaw, Poland.

For the preparation of the porphyrin based SURMOFs $\mathrm{Si}(100)$ wafers are coated with $100 \mathrm{~nm}$ gold and chemically activated by immersion in a $20 \mu \mathrm{M}$ solution of 16 mercaptohexadecanoic acid (Sigma Aldrich, Germany) in ethanol (VWR, Germany) for $72 \mathrm{~h}$, rinsed with ethanol, and dried under nitrogen. The freshly prepared and activated substrates are then coated with the porphyrin based SURMOF in a layer by layer liquid epitaxial process by spraying subsequently (1) a $1 \mathrm{mM}$ ethanolic solution of zinc acetate (Sigma Aldrich, Germany)), (2) pure ethanol for rinsing, (3) a $20 \mu \mathrm{M}$ ethanolic linker solution of 5,15 diphenyl 10,20 di(4 carboxyphenyl) porphyrin (Livchem Logistics GmbH, Germany), and (4) pure ethanol for rinsing on the substrate. This procedure is repeated 15 times. As a result a homogeneously coated substrate is obtained. For all solutions and preparation steps ultrapure ethanol was used.

HKUST 1 SURMOFs were prepared according to the procedure for the porphyrin based SURMOF mentioned above. The same preparation parameters were used for the HKUST 1 preparation with the only exception that instead of the porphyrin solution a $0.2 \mathrm{mM}$ ethanolic solution of benzene 1,4 dicarboxylic acid (BDC) was used as linker solution.

The characterization of the crystallinity of the SURMOFs was carried out by $\mathrm{X}$ ray diffraction using an the $\mathrm{Cu} \mathrm{K} \alpha_{1,2}$ radiation of $0.15419 \mathrm{~nm}$ of a Bruker D8 Advance diffractometer equipped with a Si strip detector (PSD Lynxeye) in $\theta-\theta$ geometry and a variable divergence slit on the primary side. 


\section{AUTHOR INFORMATION}

\section{Corresponding Author}

*E mail: hubertus.marbach@fau.de.

Christof Wöll: 0000000310783304

Hubertus Marbach: 0000000219829690

\section{Present Address}

${ }^{\perp}$ L.B.: Empa-Swiss Federal Laboratories for Material Science and Technology Laboratory for Mechanics of Materials and Nanostructures, Thun, $\mathrm{CH}$.

\section{Notes}

The authors declare no competing financial interest.

\section{ACKNOWLEDGMENTS}

The authors acknowledge financial support by the Deutsche Forschungsgemeinschaft (DFG) within the Cluster of Ex cellence "Engineering of Advanced Materials" (projects D7 and EXC 315/Bridge Funding), and research unit FOR 1878/ funCOS. This work was conducted within the framework of the MSCA ITN ETN 722149 (ELENA) and COST Action CM1301 (CELINA). C.W., H.G., and W.Z. thank the Chinese Science Foundation (CSC) for funding. We acknowledge the Karlsruhe Nano Micro Facility (KNMF, www.kit.edu/knmf) of the Karlsruhe Institute of Technology for provision of access to instruments at their laboratories.

\section{REFERENCES}

(1) Randolph, S. J.; Fowlkes, J. D.; Rack, P. D. Focused, Nanoscale Electron Beam Induced Deposition and Etching. Crit. Rev. Solid State Mater. Sci. 2006, 31, 55-89.

(2) Silvis Cividjian, N.; Hagen, C. W.; Kruit, P. Spatial Resolution Limits in Electron Beam Induced Deposition. J. Appl. Phys. 2005, 98, 084905.

(3) Song, M.; Furuya, K. Fabrication and Characterization of Nanostructures on Insulator Substrates by Electron Beam Induced Deposition. Sci. Technol. Adv. Mater. 2008, 9, 023002.

(4) Utke, I.; Hoffmann, P.; Melngailis, J. Gas Assisted Focused Electron Beam and Ion Beam Processing and Fabrication. J. Vac. Sci. Technol. 2008, 26, 1197-1276.

(5) Botman, A.; Mulders, J. J. L.; Hagen, C. W. Creating Pure Nanostructures from Electron Beam Induced Deposition Using Purification Techniques: a Technology Perspective. Nanotechnology 2009, 20, 372001.

(6) van Dorp, W. F.; Hagen, C. W. A Critical Literature Review of Focused Electron Beam Induced Deposition. J. Appl. Phys. 2008, 104, 081301-42.

(7) Shawrav, M. M.; Wanzenboeck, H. D.; Belic, D.; Gavagnin, M.; Bethge, O.; Schinnerl, M.; Bertagnolli, E. Mask Free Prototyping of Metal Oxide Semiconductor Devices Utilizing Focused Electron Beam Induced Deposition. Phys. Status Solidi A 2014, 211, 375-381.

(8) Gopal, V.; Radmilovic, V. R.; Daraio, C.; Jin, S.; Yang, P.; Stach, E. A. Rapid Prototyping of Site Specific Nanocontacts by Electron and Ion Beam Assisted Direct Write Nanolithography. Nano Lett. 2004, 4, 2059-2063.

(9) Belić, D.; Shawrav, M. M.; Gavagnin, M.; Stöger Pollach, M.; Wanzenboeck, H. D.; Bertagnolli, E. Direct Write Deposition and Focused Electron Beam Induced Purification of Gold Nanostructures. ACS Appl. Mater. Interfaces 2014, 7, 2467-2479.
(10) Begun, E.; Dobrovolskiy, O. V.; Kompaniiets, M.; Sachser, R.; Gspan, C.; Plank, H.; Huth, M. Post Growth Purification of Co Nanostructures Prepared by Focused Electron Beam Induced Deposition. Nanotechnology 2015, 26, 372001.

(11) Lewis, B. B.; Stanford, M. G.; Fowlkes, J. D.; Lester, K.; Plank, H.; Rack, P. D. Electron Stimulated Purification of Platinum Nanostructures Grown via Focused Electron Beam Induced Deposition. Beilstein J. Nanotechnol. 2015, 6, 907-918.

(12) Szkudlarek, A.; Rodrigues Vaz, A.; Zhang, Y.; Rudkowski, A.; Kapusta, C.; Erni, R.; Moshkalev, S.; Utke, I. Formation of Pure $\mathrm{Cu}$ Nanocrystals Upon Post Growth Annealing of $\mathrm{Cu} C$ Material Obtained from Focused Electron Beam Induced Depostion: Comparison of Different Methods. Beilstein J. Nanotechnol. 2015, 6, $1508-1517$

(13) Stanford, M. G.; Lewis, B. B.; Noh, J. H.; Fowlkes, J. D.; Rack, P. D. Inert Gas Enhanced Laser Assisted Purification of Platinum Electron Beam Induced Deposits. ACS Appl. Mater. Interfaces 2015, 7, 19579-19588.

(14) Villamor, E.; Casanova, F.; Trompenaars, P. H. F.; Mulders, J. J. L. Embedded Purification for Electron Beam Induced Pt Deposition Using $\mathrm{MeCpPtMe}_{3}$. Nanotechnology 2015, 26, 095303.

(15) Walz, M. M.; Vollnhals, F.; Rietzler, F.; Schirmer, M.; Steinrück, H. P.; Marbach, H. Investigation of Proximity Effects in Electron Microscopy and Lithography. Appl. Phys. Lett. 2012, 100, 053118-4.

(16) Plank, H.; Smith, D. A.; Haber, T.; Rack, P. D.; Hofer, F. Fundamental Proximity Effects in Focused Electron Beam Induced Deposition. ACS Nano 2012, 6, 286-294.

(17) Toth, M.; Lobo, C. J.; Knowles, W. R.; Phillips, M. R.; Postek, M. T.; Vladár, A. E. Nanostructure Fabrication by Ultra High Resolution Environmental Scanning Electron Microscopy. Nano Lett. 2007, 7, 525-530.

(18) van Kouwen, L.; Botman, A.; Hagen, C. W. Focused Electron Beam Induced Deposition of $3 \mathrm{~nm}$ Dots in a Scanning Electron Microscope. Nano Lett. 2009, 9, 2149-2152.

(19) van Dorp, W. F.; van Someren, B.; Hagen, C. W.; Kruit, P.; Crozier, P. A. Approaching the Resolution Limit of Nanometer Scale Electron Beam Induced Deposition. Nano Lett. 2005, 5, 1303-1307.

(20) van Oven, J. C.; Berwald, F.; Berggren, K. K.; Kruit, P.; Hagen, C. W. Electron Beam Induced Deposition of $3 \mathrm{~nm}$ Half Pitch Patterns on Bulk Si. J. Vac. Sci. Technol., B: Nanotechnol. Microelectron.: Mater. Process., Meas., Phenom. 2011, 29, 06F305.

(21) Marbach, H. Electron Beam Induced Surface Activation: a Method for the Lithographic Fabrication of Nanostructures via Catalytic Processes. Appl. Phys. A: Mater. Sci. Process. 2014, 117, 987-995.

(22) Walz, M. M.; Schirmer, M.; Vollnhals, F.; Lukasczyk, T.; Steinrück, H. P.; Marbach, H. Electrons as "Invisible Ink": Fabrication of Nanostructures by Local Electron Beam Induced Activation of SiOx. Angew. Chem., Int. Ed. 2010, 49, 4669-4673.

(23) Walz, M. M.; Vollnhals, F.; Schirmer, M.; Steinrück, H. P.; Marbach, H. Generation of Clean Iron Nanocrystals on an Ultra Thin SiOx Film on Si(001). Phys. Chem. Chem. Phys. 2011, 13, 1733317338.

(24) Muthukumar, K.; Jeschke, H. O.; Valenti, R.; Begun, E.; Schwenk, J.; Porrati, F.; Huth, M. Spontaneous Dissociation of $\mathrm{Co}_{2}(\mathrm{CO})_{8}$ and Autocatalytic Growth of $\mathrm{Co}$ on $\mathrm{SiO}_{2}$ : A Combined Experimental and Theoretical Investigation. Beilstein J. Nanotechnol. 2012, 3, 546-55.

(25) Vollnhals, F.; Woolcot, T.; Walz, M. M.; Seiler, S.; Steinrück, H. P.; Thornton, G.; Marbach, H. Electron Beam Induced Writing of Nanoscale Iron Wires on a Functional Metal Oxide. J. Phys. Chem. C 2013, 117, 17674-17679.

(26) Vollnhals, F.; Wintrich, P.; Walz, M. M.; Steinrück, H. P.; Marbach, H. Electron Beam Induced Surface Activation of Ultrathin Porphyrin Layers on $\mathrm{Ag}(111)$. Langmuir 2013, 29, 12290-12297.

(27) Drost, M.; Tu, F.; Vollnhals, F.; Szenti, I.; Kiss, J.; Marbach, H. On the Principles of Tweaking Nanostructure Fabrication via Focused Electron Beam Induced Processing Combined with Catalytic Growth Processes. Small Methods 2017, 1, 1700095. 
(28) Vollnhals, F.; Drost, M.; Tu, F.; Carrasco, E.; Späth, A.; Fink, R.; Steinrück, H. P.; Marbach, H. Electron Beam Induced Deposition and Autocatalytic Decomposition of $\mathrm{Co}(\mathrm{CO})_{3} \mathrm{NO}$. Beilstein J. Nanotechnol. 2014, 5, 1175-1185.

(29) Gliemann, H.; Wöll, C. Epitaxially Grown Metal Organic Frameworks. Mater. Today 2012, 15, 111-116.

(30) Liu, J. X.; Wöll, C. Surface Supported Metal Organic Frame work Thin Films: Fabrication Methods, Applications, and Challenges. Chem. Soc. Rev. 2017, 46, 5730-5770.

(31) Kitagawa, S.; Kitaura, R.; Noro, S. Functional Porous Coordination Polymers. Angew. Chem., Int. Ed. 2004, 43, 2334-2375.

(32) Rowsell, J. L. C.; Yaghi, O. M. Metal Organic Frameworks: a New Class of Porous Materials. Microporous Mesoporous Mater. 2004, 73, 3-14.

(33) Wang, X. S.; Ma, S.; Forster, P. M.; Yuan, D.; Eckert, J.; López, J. J.; Murphy, B. J.; Parise, J. B.; Zhou, H. C. Enhancing $\mathrm{H}_{2}$ Uptake by "Close Packing" Alignment of Open Copper Sites in Metal Organic Frameworks. Angew. Chem., Int. Ed. 2008, 47, 7263-7266.

(34) Mueller, U.; Schubert, M.; Teich, F.; Puetter, H.; Schierle Arndt, K.; Pastré, J. Metal Organic Frameworks Prospective Industrial Applications. J. Mater. Chem. 2005, 16, 626-636.

(35) Furukawa, H.; Ko, N.; Go, Y. B.; Aratani, N.; Choi, S. B.; Choi, E.; Yazaydin, A. Ö.; Snurr, R. Q.; O'Keeffe, M.; Kim, J.; Yaghi, O. M. Ultrahigh Porosity in Metal Organic Frameworks. Science 2010, 329, 424-427.

(36) Czaja, A. U.; Trukhan, N.; Müller, U. Industrial Applications of Metal Organic Frameworks. Chem. Soc. Rev. 2009, 38, 1284-1293.

(37) Stassen, I.; Burtch, N. C.; Talin, A. A.; Falcaro, P.; Allendorf, M. D.; Ameloot, R. An Updated Roadmap for the Integration of Metal Organic Frameworks with Electronic Devices and Chemical Sensors. Chem. Soc. Rev. 2017, 46, 3853-3853.

(38) Shekhah, O.; Wang, H.; Zacher, D.; Fischer, R. A.; Wöll, C. Growth Mechanism of Metal Organic Frameworks: Insight into the Nucleation by Employing a Step by Step Route. Angew. Chem., Int. Ed. 2009, 48, 5038-5041.

(39) Wang, Z. B.; Liu, J. X.; Lukose, B.; Gu, Z. G.; Weidler, P. G.; Gliemann, H.; Heine, T.; Wöll, C. Nanoporous Designer Solids with Huge Lattice Constant Gradients: Multiheteroepitaxy of Metal Organic Frameworks. Nano Lett. 2014, 14, 1526-1529.

(40) Zhou, W.; Wöll, C.; Heinke, L. Liquid and Gas Phase Diffusion of Ferrocene in Thin Films of Metal Organic Frameworks. Materials 2015, 8, 3767.

(41) Liu, J.; Wächter, T.; Irmler, A.; Weidler, P. G.; Gliemann, H.; Pauly, F.; Mugnaini, V.; Zharnikov, M.; Wöll, C. Electric Transport Properties of Surface Anchored Metal-Organic Frameworks and the Effect of Ferrocene Loading. ACS Appl. Mater. Interfaces 2015, 7, 9824-9830.

(42) Munuera, C.; Shekhah, O.; Wang, H.; Wöll, C.; Ocal, C. The Controlled Growth of Oriented Metal Organic Frameworks on Functionalized Surfaces as Followed by Scanning Force Microscopy. Phys. Chem. Chem. Phys. 2008, 10, 7257-7261.

(43) Balaur, E.; Djenizian, T.; Boukherroub, R.; Chazalviel, J. N.; Ozanam, F.; Schmuki, P. Electron Beam Induced Modification of Organic Monolayers on $\mathrm{Si}(111)$ Surfaces Used for Selective Electrodeposition. Electrochem. Commun. 2003, 6, 153-157.

(44) Turchanin, A.; Käfer, D.; El Desawy, M.; Wöll, C.; Witte, G.; Gölzhäuser, A. Molecular Mechanisms of Electron Induced Cross Linking in Aromatic SAMs. Langmuir 2009, 25, 7342-7352.

(45) Geyer, W.; Stadler, V.; Eck, W.; Zharnikov, M.; Gölzhäuser, A.; Grunze, M. Electron Induced Crosslinking of Aromatic Self Assembled Monolayers: Negative Resists for Nanolithography. Appl. Phys. Lett. 1999, 75, 2401-2403.

(46) Sanche, L. Irradiation of Organic and Polymer Films with Low Energy Electrons. Nucl. Instrum. Methods Phys. Res., Sect. B 2003, 208, 4-10.

(47) Friedli, V.; Utke, I. Optimized Molecule Supply from Nozzle Based Gas Injcetion Systems for Focused Electron and Ion Beam Induced Deposition and Etching: Simulation and Experiment. J. Phys. D: Appl. Phys. 2009, 42, 1-10. 


\section{Repository KITopen}

Dies ist ein Postprint/begutachtetes Manuskript.

Empfohlene Zitierung:

Drost, M.; Tu, F.; Berger, L.; Preischl, C.; Zhou, W.; Gliemann, H.; Wöll, C.; Marbach, H. Surface-Anchored Metal-Organic Frameworks as Versatile Resists for Gas-Assisted E-Beam Lithography: Fabrication of Sub-10 Nanometer Structures.

2018. ACS nano, 12

doi:10.5445/IR/1000086738

Zitierung der Originalveröffentlichung:

Drost, M.; Tu, F.; Berger, L.; Preischl, C.; Zhou, W.; Gliemann, H.; Wöll, C.; Marbach, H. Surface-Anchored Metal-Organic Frameworks as Versatile Resists for Gas-Assisted E-Beam Lithography: Fabrication of Sub-10 Nanometer Structures.

2018. ACS nano, 12 (4), 3825-3835.

doi:10.1021/acsnano.8b01071 